\title{
Perceptions of Fashion Interns: Roles, Responsibilities, Expectations and Experiences
}

\author{
Japjee Kaur Kohli
}

Associate Professor, Fashion Design Dept., National Institute of Fashion Technology, Gandhinagar, India. Email:japjee_kaur@yahoo.co.in Tel:91-9558473242

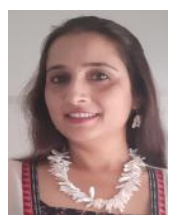

\begin{abstract}
Fashion design education has grown by leaps and bounds across world in recent years. It aims to prepare students with knowledge, skills and attitudes (KSA) to work in fashion industry and be employable. To empower students with much needed KSA, fashion design programs have industrial internship as a mandatory requirement that enables students to receive experiential training within the industry for a specific period. Industry internship is an opportunity to gain first- hand experience about various activities and operations conducted in an organization to manufacture products. This research investigates the perceptions of fashion design students regarding their expectations and experiences from an industrial internship using a mixed method approach. Structured questionnaires and semi structured interview schedule is used to gather data. Sample size for questionnaire was 66 and later in-depth interviews were conducted with 16 students. The findings of this research provide rich insight on internship expectations and experiences that can help educational institutions and fashion industry to work collaboratively in order to strengthen the internship program and maximize the benefits.
\end{abstract}

Keywords: Fashion design education, Industrial internship, Skill, Experiential learning, Curriculum, KSA

Citation | Japjee Kaur Kohli (2019). Perceptions of Fashion Interns: Roles, Responsibilities, Expectations and Experiences. Asian Journal of Education and Training, 5(4): 501-509.

History:

Received: 3 July 2019

Revised: 9 August 2019

Accepted: 20 September 2019

Published: 16 Octember 2019

Licensed: This work is licensed under a Creative Commons

Licensed: This work is licen
Attribution 3.0 License (cc) BY

Publisher: Asian Online Journal Publishing Group
Funding: This study received no specific financial support.

Competing Interests: The author declares that there are no conflicts of interests regarding the publication of this paper.

Transparency: The author confirms that the manuscript is an honest, accurate, and transparent account of the study was reported; that no vital features of the study have been omitted; and that any discrepancies from the study as planned have been explained.

Ethical: This study follows all ethical practices during writing.

\section{Contents}

1. Introduction

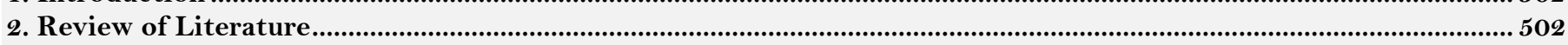

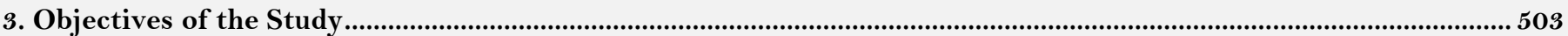

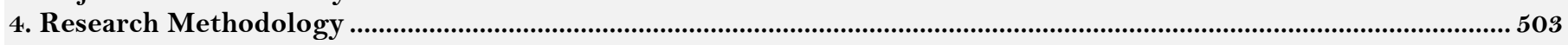

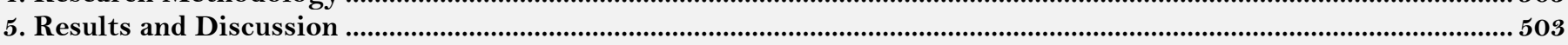

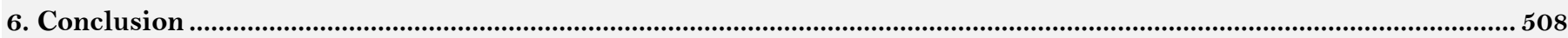

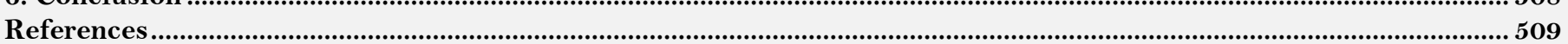




\section{Contribution of this paper to the literature}

This study contributes to the existing literature by investigating the perceptions of fashion design interns using structured questionnaire and interview schedule. The in-depth analysis throws light on the roles, responsibilities, expectations and experiences of interns in Indian fashion industry. Not much literature is available in context of Indian fashion industry.

\section{Introduction}

Industrial internship forms an integral part of an academic curriculum for developing competencies in any vocational discipline. It is an opportunity for students to experience real world professional environment. Several studies and reports indicate skill gap among student trainees across varied sectors. Skill gap suggest that student trainees lack knowledge, skill and attitude (KSA) to work in actual work environment, thus, pointing towards negative aspect of job market readiness. An internship program is designed in higher learning institutions with the aim to allow trainees to work in industrial environment and apply academic learning to real world experiences in order to make informed decisions besides developing general as well as job specific skills that make them employable. This paper attempts to study the perceptions of fashion design students towards their expectations and experiences from industrial internship program. Further, suggestions to make internship program more fruitful and valuable are discussed.

\section{Review of Literature}

Experiential learning experiences such as internship have been a significant factor in the active learning process by influencing the knowledge and enhancing the skills of students. Internship is defined by various authors as a 'supervised work experience' (McMahon and Quinn, 1995; Renganathan et al., 2012) as an opportunity to fill gap between learning and real world of work (D'abate et al., 2009) as a means to transform student knowledge (Fox, 2001; Gavigan, 2010) as learning by doing (O’Neill, 2010) and, as a form of experiential learning or field experience (Pauzé et al., 1989). Numerous studies have been conducted that discuss various dimensions of internship such as experiences, benefits to stakeholders, project based approach, career oriented curriculum, and expectations in different sectors like hospitality and tourism, leisure management, business management, accounting, nursing, design, LIS, IT etc. 11 dimensions of internship program were identified while elaborating on the potential benefits and costs of internships to interns, employers, faculty and schools (Maertz et al., 2014). Opportunity to learn, realistic knowledge about industry working, experiential learning and probability of job offer from employer were identified as potential benefits to the intern. Self- initiative, academic preparedness and positive attitude were identified as strongest individual factors determining internship effectiveness by Phoebe (2010).

Internship experiences and their impact on practical skill development among student trainees were explored by Edonkumoh et al. (2015). Researchers found that internship training exposed trainees to modern ICTs being used in libraries thus, enhancing ICT skills. Kardash (2000) evaluated a set of 14 research skills and found that the basic scientific skills were enhanced due to internship. Highest ratings were found in: observing and collecting data, understanding importance of controls, interpreting data, orally communicating the results of research project and thinking independently. He further argued that undergraduate research experiences enhance interns' abilities to engage in 'real work' as it provides an authentic learning experience.

Karunaratne and Perera (2015) explored the effectiveness of industrial internship experienced by undergraduates from the Department of Textiles, who had interned with leading apparel manufacturers in Sri Lanka. Findings revealed positive learning experiences, building professional relationship, collaborative learning, deeper understanding of work culture, skill development like problem solving, increase in self- confidence, better inter-personal skills, and increased interest in future education and career. The findings also highlighted negative side indicating lesser opportunities to develop creative skills, managerial abilities, team work abilities, project and research skills, lack of knowledge about functioning and exposure to other departments of the company. Mercan et al. (2015) found that undergraduate students were satisfied with their internships and they considered internship as an important opportunity to learn job, create better professional relationship, and higher probability of converting into full time job in the same company. Internship increased self- confidence, developed positive thoughts about the industry and profession, enhanced communication skills. Students appreciated learning benefits achieved from internship.

Internships helped to build and refine specific research skills such as survey design or qualitative data analysis, learn professional skills that can be applied in future careers, develop professional connections, find employment, and bring a positive change for organizations/ society (Hynie et al., 2011). Improvements like longer duration of internship and increased mentorship were also suggested by students for making internships more effective. Bye and Labat (2005) stated that integrated studio approach incorporating active learning methods such as experimentation enabled students to develop creative, technical, and problem solving skills besides functional skills like working in teams, change adaptability, interpersonal skills, decision making and professional skills. Kozar and Hiller (2015) noted high satisfaction level among students from internship as it enhanced learning, developed skills and abilities besides increasing their confidence, helping to identify their professional goals, career aspirations and talents. The researcher reported that internship was highly effective in strengthening the foundational knowledge through real life work situations. Knouse and Fontenot (2008) found that internships enhanced employability. Researcher further stated that challenging projects, continuous feedback, exposure to varied fields and higher learning satisfaction offered greater success during internship. Clarity about task, open and participative work environment and respectful treatment are motivating factors that generate interest among internees.

The literature indicates that little research has been conducted w.r.t fashion design course and fashion design internships in Indian context. There is a need to understand the internship requirements, expectations, experiences, and effectiveness in a fashion design program in Indian scenario as Indian fashion/apparel industry is second largest employment generator. According to Ministry of Textiles (2018) by 2025, education wise human 
resource requirement in garmenting sector would be 0.23 million (vocational/ diplomas), 0.56 million (graduates) and 0.10 million post graduates. Job roles for these educational levels would include line supervisors, designers, sampling and production merchandisers, production managers and quality controllers. It is evident that there is huge employment potential and therefore, emphasis should be on career oriented curriculum where internships add value to the students' learning experience.

\section{Objectives of the Study}

The following objectives were established to be studied:

1. To understand the internship requirements in a fashion design program.

2. To find out the expectations of fashion design students while looking for internship.

3. To explore the experiences gained during internship.

4. To suggest improvements to make internship program more effective.

It is anticipated that the findings will be helpful to curriculum planners, industry and future students.

\section{Research Methodology}

The study investigated the perceptions of 66 fashion design students of NIFT, Gandhinagar from two batches (2018 and 2019 internship track). Internship is scheduled at the completion of $3^{\text {rd }}$ year and before commencement of $4^{\text {th }}$ year of study for a period of 8 weeks. Data pertaining to expectations was collected before joining internship in May 2018 and 2019. Data related to experiences during internship were gathered once the students were back from internship program in the month of August 2018 and 2019. Since population size is small, the entire populations (both batches) were used for survey. Only 66 completely filled questionnaires have been used for the study. Students who completed their internship in 2018 have graduated and students who underwent internship in 2019 are pursuing their $4^{\text {th }}$ year of fashion design degree.

Mixed method approach, comprising of survey and interview was adopted to collect the information. Based on objectives and curriculum requirements, a structured questionnaire was developed for survey. It was validated by two experts from fashion design department. The final instrument was directly administered by the researcher to the respondent students and immediately collected upon completion. The survey data was collected at two phases: pre- internship and post internship. The response rate was $93 \%$ for pre-internship and $87.5 \%$ in post internship survey. Post survey, in-depth interviews using semi structured interview schedule were conducted. It provides scope for cross- questioning and reframing of questions to obtain relevant and in-depth information about their roles, responsibilities, expectations and experiences. The data was analyzed using descriptive statistics.

\subsection{Data Collection}

Surveys: All students gathered in Lecture room and survey questionnaire was distributed among them. The researcher briefed the students about the purpose of collecting data. Questionnaire was divided into two parts: demographics and psychographics. Demographics, comprised of 7 questions that dealt with respondent attributes such as age, gender, type of organization, preference of organization, department assigned during internship period, product category, stipend and other benefits paid. Psychographics section comprised of 4 dichotomous questions, 8 open ended questions, and 2 questions based on 3-point rating scale. Dichotomous questions asked respondents whether their expectations were met, difficulty faced in arranging internships, duration of internship period. The open ended questions allowed respondents to provide information on their roles and responsibilities, expectations from internship, positive and negative experiences, types of projects handled, work environment, any changes observed in their KSA, job possibilities and progress possibilities in professional capacity.

Interviews: Purposive sampling was used for interview. Only 16 students from entire population were selected for in-depth interview. Names have been coded to protect the identity of the respondent. Interview was conducted by the researcher in campus and was hand recorded. Care was taken that sample represented all 3 types of organizations falling under fashion industry. Interview schedule had 5 semi-structured questions. These questions pertained to their good as well as bad experiences, specific job role, and difficulties faced by them during internship. Table 1 provides details of the sample used in the present study. 45 and 21 students participated in the survey from 2018 and 2019 batch respectively. For interview schedule, 10 students from 45 participants of 2018 batch and 6 students from 21 participants of 2019 batch were selected.

\begin{tabular}{l|c|c|c}
\multicolumn{4}{c}{ Table-1. Sample size of the present study. } \\
\hline \multirow{3}{*}{\begin{tabular}{c} 
Number of respondents \\
\cline { 2 - 4 }
\end{tabular}} & Year & Survey & Interview \\
\cline { 2 - 4 } & 2018 internship & 45 & 10 \\
\hline \multicolumn{2}{c}{ Total respondents } & 21 & 6 \\
\hline
\end{tabular}

\section{Results and Discussion}

Results of survey and interview are analyzed to answer the research objectives.

\subsection{Internship Requirements}

NIFT offers 2 months ( 8 weeks) internship program to students who have completed their $3^{\text {rd }}$ year of study. By the completion of $3^{\text {rd }}$ year, students are well versed with various courses, have gained knowledge and developed skills such as pattern making, garment construction, ideation and sketching, history of fashion, surface design, draping, merchandising, and production systems. First 2 weeks of internship program allow students to get an exposure to various departments, overall functioning of the company and then student is assigned a particular department, preferably design or merchandising department. For the remaining six weeks, students work on different projects that are assigned by company mentors besides developing a range on the basis of the design brief 
given by the company. Post completion of internship, student has to present the work in front of jury panel for evaluation of the same. Qualitative feedback is provided by Industry Mentor to the Fashion Design department.

\subsection{Survey \&̊ Intervierw Findings}

A total of 66 students participated in survey. Demographic details of respondents are presented in Table 2.

Table-2. Demographic details of respondents.

\begin{tabular}{|c|c|c|c|}
\hline \multicolumn{2}{|c|}{ Demographic details of respondents } & \multirow{2}{*}{$\frac{\text { Frequency }}{38}$} & \multirow{2}{*}{$\frac{\text { \%age }}{57.5}$} \\
\hline Age (in years) & $20-21$ & & \\
\hline & $22-23$ & 18 & 27.3 \\
\hline & $24-25$ & 10 & 15.2 \\
\hline \multirow[t]{2}{*}{ Gender } & Male & 6 & 9.1 \\
\hline & Female & 60 & 90.9 \\
\hline \multirow[t]{4}{*}{ Type of organization } & Design house & 14 & 21.2 \\
\hline & Export house & 22 & 33.3 \\
\hline & Domestic manufacturing unit/ brand & 29 & 44.0 \\
\hline & Any other & 1 & 1.51 \\
\hline \multirow[t]{6}{*}{ Category } & Womenswear & 44 & 66.6 \\
\hline & Menswear & 5 & 7.57 \\
\hline & Kids wear & 5 & 7.57 \\
\hline & Both womenswear and menswear & 8 & 12.1 \\
\hline & Both womenswear and kidswear & 3 & 4.54 \\
\hline & All three categories & 1 & 1.51 \\
\hline \multirow[t]{2}{*}{ Stipend } & Paid & 15 & 22.7 \\
\hline & Not paid & 51 & 77.2 \\
\hline \multirow[t]{2}{*}{ Other benefits } & Yes & 6 & 9.1 \\
\hline & No & 60 & 90.9 \\
\hline \multirow[t]{2}{*}{ Difficulty in arranging internship } & Yes & 14 & 21.2 \\
\hline & No & 52 & 78.7 \\
\hline
\end{tabular}

Fashion design is an under graduate 4 year degree program. The eligibility to join program is successful completion of XII standard. It is apparent from Table 2 that $57.5 \%$ respondents were in the age group of $20-21$ years. Data revealed that $90.9 \%$ respondents were females. It was evident that $21.2 \%$ student respondents interned in a design house, $33.3 \%$ in export units, $44 \%$ in domestic manufacturing/ brand and remaining $1.51 \%$ in other types of organizations engaged in retail or e-commerce. It was also observed that maximum students $(66.6 \%)$ worked in womenswear category. Data pertaining to stipend and other benefits revealed that most companies in apparel/ fashion sector do not provide any kind of benefits or financial support to the interns. Only 22.7\% received stipend and the companies that paid stipend were brands like Madura Fashion \& Lifestyle, Arvind Fashion Ltd., Craftsroots, Three Clothing, Ridhi Majithia, Vedic Apparels, A Little Fable, Raymond, Code 61. Regarding benefits, only $9.1 \%$ students were offered benefits such as reimbursement of travel cost of company sent them to processing unit, lunch, attending an event to get exposure, and transport in company bus. $21.2 \%$ students faced difficulty in arranging their internships. The reasons described included late response from companies despite regular follow-up mails; internee seats were already full in that company, no response from design house and had to opt for brand manufacturer, and location limitation.

\subsection{Expectations from Internship}

Finding an internship opportunity as per ones expectations builds pressure on any student as it impacts their career aims and future goals. 6 students $(9.09 \%)$ mentioned that their expectations were not met. Reasons for disappointment as stated included- less design related opportunity; little exposure to overall functioning; no inputs regarding costing, pricing and sourcing; samples not developed in their presence; assigned merchandising department instead of design; industry mentor was quite rude to her, little inputs in design as she was asked to work in merchandising department, bad work space for internee, time wastage due to slow decision making process at management's end, lack of mentoring, little feedback, and no learning as she ran on errands and was given tasks that did not offer much responsibility or learning. Remaining $90.9 \%$ were satisfied with their internship as their expectations related to learning and industry exposure got fulfilled.

Three areas emerged from survey findings with respect to expectations of the students. First theme emerged focused upon improvement in knowledge, skills and attitude (KSA) to perform in apparel/ fashion companies. Students considered internship as an important step in achieving their career goals as it would enhance their abilities to work in industrial setting, develop abilities to interact, communicate and handle situations at work place, provide opportunity to work individually as well as in teams, develop survey and research skills. Our findings are supported by Schambach and Dirks (2002) study who found that internship experience helped students achieve the following: confidence in skills and capabilities, increased awareness of much needed skills at workplace, enhanced interpersonal and technical skills. Knouse and Fontenot (2008) also found that internships enable students to develop desired skills through practical experience. Phoebe (2010) found self- initiative, academic preparedness and positive attitude as success factors for achieving internship satisfaction. Summary of survey w.r.t. KSA is as follows:

Skills developed- handling workers, how to lowering cost of production, design process, presentation skills, communication, work while maintaining deadlines, market research, CAD skills, research and analysis, designing embroidery designs for various markets, managerial skills, handling orders, technical drawing, developing samples. 
Knowledge enhanced- documentation, business aspect of design, different types of embroideries and layouts, fabrics understanding, creating tech-packs, khakha development, mitering in garments, social media marketing, knowledge of denim washes, industry systems and functioning.

Attitude gained- time management, work ethics, taking responsibility, team work, punctuality, sincerity, quick learner, enthusiasm.

Second theme emerged described their interest in experiential learning. As a part of curriculum, students had visited companies under various courses such as Fabric Fundamentals, Surface Design, Apparel Production, Merchandising Systems, Quality Systems. Such visits provided an over view of the topic under study. $100 \%$ students were quite excited w.r.t. their internship. They considered it as an opportunity to learn the functioning of a garment manufacturing in a unit, infrastructural and human resource set up required, departments involved and their roles, various job roles, functioning of design team, accomplishing orders within stipulated times, sourcing, planning activities apart from gaining marketable job experience,. Most importantly, students were highly interested to learn about the design process followed in these companies based on client briefs. Studies strengthen our findings that experiential learning allows better clarity of classroom concepts when applied practically (Schambach and Dirks, 2002) improvement in knowledge about company and work habits, valuable real world experience, greater understanding of potential employers, better understanding of job roles and career prospects (Maertz et al., 2014) as 'live workforce training' (Burns, 2013). Findings cited by Faerm (2014) project internships as helpful, realistic professional experience that provides greater exposure to professional environment and develops an understanding of working under another designer.

Third theme revealed that students expected greater inputs and opportunities in design field. Being a student of Fashion Design program, students expected that they would be involved in design department. As an active learning 'real world' experience, students expected greater inputs on design process, execution of a range for the designer, learn to handle clients, designing garments for the company and interaction with buyer. Students who were working in a design house got ample opportunities to design. These projects included developing tech-packs, creating social media profiles, embroidery and motif development, creating range, handle sampling, pattern and khakha development, new design development with left over fabrics.

\subsection{Internship Experience}

Since internship is a mandatory credit course, it was necessary to know up to what extent students were able to relate institutional learning with industrial experiential learning. This required an analysis of relationship between their job roles and courses studied by them.

Table 3 illustrates percentage and mean score of respondents who mentioned 'to great extent' on a three point scale that questioned the level of application of educational learning to their job roles.

Table-3. Application of educational learning to their job role.

\begin{tabular}{l|c|c}
\hline Item & \% To great extent & Mean score \\
\hline Draping & 15.1 & 2.43 \\
\hline Pattern making & 54.5 & 1.56 \\
\hline Garment construction & 77.2 & 1.31 \\
\hline Surface ornamentation & 63.6 & 1.45 \\
\hline Design process & 93.9 & 1.06 \\
\hline Fabric knowledge & 81.8 & 1.25 \\
\hline Sketching \& illustration & 74.2 & 1.34 \\
\hline Use of IT skills for documentation & 53.0 & 1.65 \\
\hline Use of design software for digital design development & 46.9 & 1.74 \\
\hline Merchandising process and documentation & 40.9 & 1.77 \\
\hline Manufacturing process & 77.2 & 1.30 \\
\hline
\end{tabular}

Responses in Table 3 demonstrated that 'design process' was the most useful academic learning that was widely used in the industry and they could work on projects without much difficulty. They could easily relate and work comfortably. 94\% students agreed that design process is 'used to great extent' in the industry irrespective of garment category or type of organization. In fact, they have refined their skills in design process and are more comfortable to present their research and findings on identifying trends, silhouette, defining client profile, season, range design, and presenting these boards to clients or management during meetings. $82 \%$ responses showed near unanimous agreement that 'Fabric knowledge' is extremely important in fashion/ apparel industry. Designer or merchandiser has to work with fabrics and therefore, possessing good knowledge about fabric behavior, characteristics, uses, sourcing destinations is a must. 'Garment construction' and 'knowledge of manufacturing process' scored third highest. $77.2 \%$ agreed that working in fashion industry requires sound knowledge of garment construction and manufacturing systems. To execute a design, a designer should be well aware of garment construction methods that include varieties of seams, hand and machine finishes, steps in construction, material requirement. Student's responses indicated that they were comfortable in getting the designs or range executed as they had already learnt skills during academic learning. It was easier for them to guide tailors and work with pattern masters while getting design executed. This was followed by sketching and illustration (74.2\%), surface ornamentation $(63.6 \%)$. Table demonstrated that Draping had least utility in the industry. $15 \%$ stated draping technique as 'to a great extent' whereas $59 \%$ mentioned as 'very little'. Thorough investigation of responses revealed that students who were working in a design house mentioned that draping was used 'to a great extent' as each design is unique and is developed using draping technique or a combination of draping and pattern making. The responses of students who were in export house or brand manufacturing units stated that draping technique was least or not at all used in their companies.

Every student had her/his own share of good and bad experiences during internship. Table 4 illustrates some of the experiences mentioned by internees in their questionnaire. Based on these responses, students were selected for conducting interviews in second phase. Interviews conducted elaborated in detail about the experiences. Most 
students stated to have positive experience, $27 \%$ did mention about bad experiences. It was evident from findings that internship was a valuable experience for students. It helped them relate classroom learning with real life experience making the learning more authentic. Internships yield greater benefits to students by enhancing their skills, better employment opportunities, greater understanding of concepts, increased knowledge, working pattern of companies, besides developing capabilities that cannot be developed in a classroom setting such as: work delegation, leadership, teamwork, work ethics, dealing with people, inter-personal skills, and workplace hazards.

\begin{tabular}{|c|c|}
\hline Good experiences & Bad experiences \\
\hline $\begin{array}{l}\text { - Friendly and healthy environment } \\
\text { - Gained production knowledge specially denim washes } \\
\text { - All } 40 \text { designs made were approved and sent for mass } \\
\text { production } \\
\text { - Met designers and opportunity to attend trade show SS'19 } \\
\text { - Freedom to explore resources and design } \\
\text { - Time management and getting work done from others } \\
\text { - Learnt initiative taking, sincerity and behaviourial skills } \\
\text { - Full guidance and cooperation from designer } \\
\text { - Learnt how a startup works and its teething problems } \\
\text { - Learnt handling social media for a brand } \\
\text { - Learnt people handling such as tailors or working with } \\
\text { master } \\
\text { - Learnt problem solving and time management } \\
\text { - Networking and made connections } \\
\text { - Exposure to realities of making garments } \\
\text { - Increased confidence in professional skills } \\
\text { - Improved vocational skills } \\
\text { - Enhanced communication skills } \\
\text { - Increased ability to deal with different people at various } \\
\text { levels } \\
\text { - Some level of autonomy in responsibilities }\end{array}$ & $\begin{array}{l}\text { - Travelling in local buses } \\
\text { - No helper was provided, had to remove big and } \\
\text { heavy rolls by myself } \\
\text { - Asked to do packaging with employees for a } \\
\text { shipment } \\
\text { - Rude behavior of mentor } \\
\text { - Not sufficient design inputs as expected } \\
\text { - Worked as runner most of the times } \\
\text { - Many times no work due to off- season } \\
\text { - Made to do their work and also over time } \\
\text { - Felt under- utilized and some days I was bored }\end{array}$ \\
\hline
\end{tabular}

To gain an understanding of various aspects related to experiential learning during internship program, students were asked to rate each of the 11 parameters on a three point rating scale (satisfactory-1, good-2, very good-3). Figure 1 illustrates the experience regarding each item.

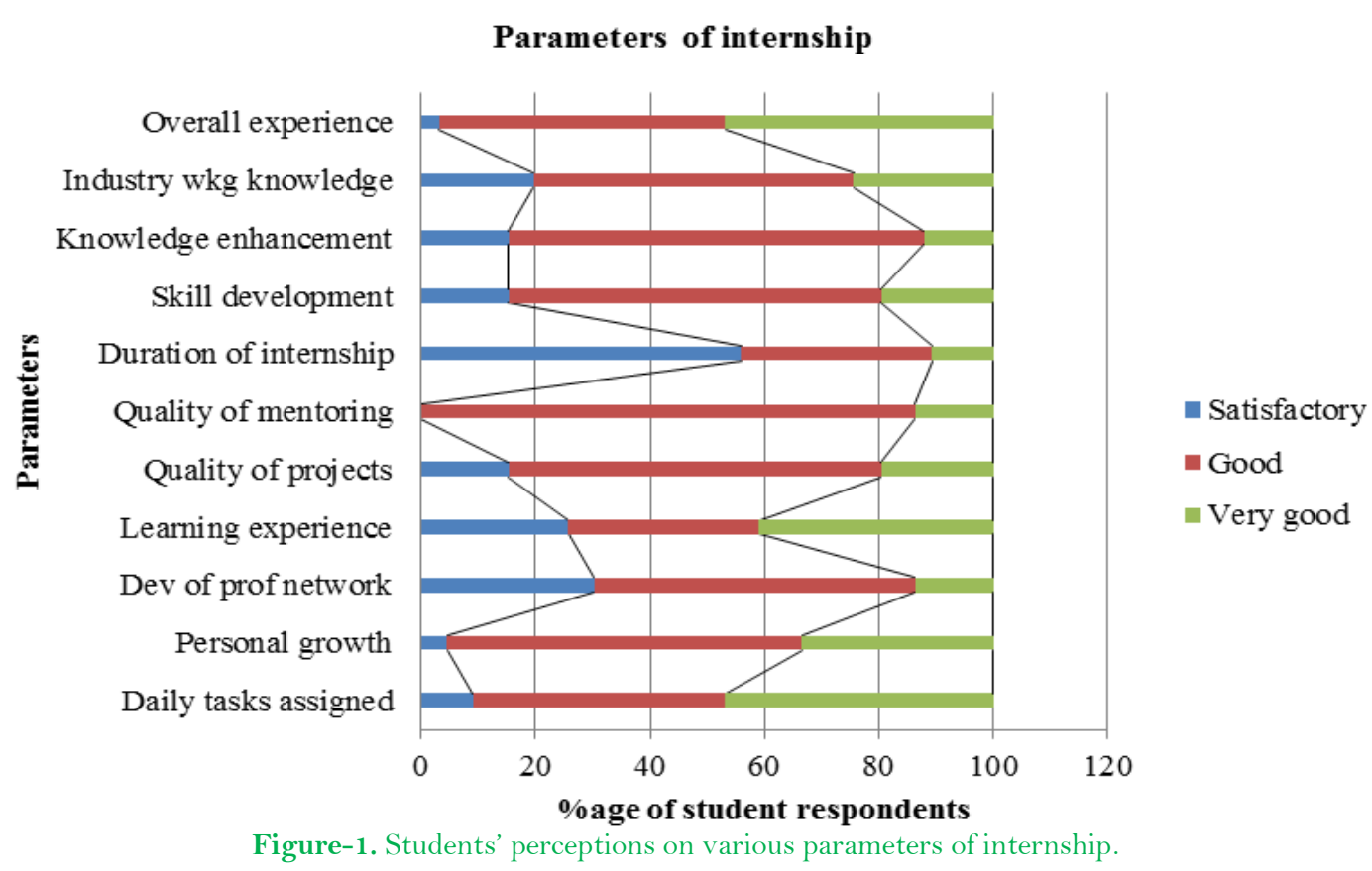

It is evident from the Figure 1 that responses were inclined towards 'good experience' in all items. Highest mean score (2.37) was found in 'daily tasks assigned'. Respondents found daily tasks as meaningful and valuable to their learning process. These tasks added to their personal growth (mean score $=2.28$ ). The internship program was considered as an ultimate learning experience (mean score $=2.15$ ) that added new dimensions to their thought process and academic learning.

All respondents had good (86.3\%) to very good (13.7\%) experience with their mentors. Respondents were quite satisfied with their industry mentors for quality of mentoring and timely guidance. This has helped them to value time, apply their learning in an effective manner, and grasp better understanding of working systems and practices besides completing projects on time. $72.6 \%$ and $65.1 \%$ reported knowledge enhancement and skill development respectively. Quality of projects was marked as 'good' by $65.1 \%$ of students.

Duration of internship was one aspect that showed 'satisfactory' results. $56 \%$ students felt that the 2 months duration is too less to get hands on experience at the industry. Students were of the opinion that internship duration should be increased to 4 months. This will provide them ample opportunity to adjust in work 
environment, get exposure to all departments, more number of tasks or projects to work upon, better development of skills and knowledge, more exposure to company's activities.

Survey findings showed that internship helped build skills, knowledge and attitude among respondents, provided a rich opportunity to experience real world of work, responsibly work on the job role provided during internship and be able to relate and apply their academic learning while working on tasks assigned. Further, interviews were conducted with selected sample to gainer deeper insight on the perceptions of students regarding expectations and experiences from an internship program and the findings are presented in verbatim quotations. This allowed richness in the data collected. The interview focused on the following aspects:

- Roles, responsibilities and projects handled.

- Expectations.

- Experiences.

- Perceptions.

Roles, Responsibilities \& Projects handled:

$\mathrm{S} 1$ : I interned in a brand house and created collection of menswear shirt incorporating prints, silhouette, trims besides developing a trend direction book and product shoots.

S2: I look into the entire design process for the brand, creating tech-packs, follow-ups, independently handling sampling unit and market survey. I worked on 4 design projects based on crafts.

S3: I interned in a design house. My role required me to handle social media for the company- Instagram and Facebook; designing garments for upcoming fashion week; provide ideas for packaging; and suggest ideas for utilization of left over fabrics.

S4: I interned with a renowned fashion designer. I was asked to research on ready to wear line along with couture, create art installation ideas for their upcoming store based on their brand identity, developed presentation boards for invites and digital media and FDCI presentation for upcoming event. I was lucky to experience and work for India Couture Week collection. Shared ideas and developed artworks for the collection, selected artworks were sent for sampling where I worked on khakha making, creative surface development, provided colour and material options, finishing and fittings for the show, packing garments and sending to the show venue. On the day of fashion show, I worked back stage and looked after immediate alterations, lineups, immediate changes required.

S5: My interest was to work in an export house and I worked for a US Brand in woven category. I was responsible for developing surfaces using different embellishment materials and colours. I was also looking after placement of orders for computerized embroidery, trims, and fabrics. Buyer's brief was handed over to me to work accordingly.

S6: My role in the export house required me to conduct research on trend directions, get the samples made, and look after sourcing of various materials and development of surfaces and embroidery designs as per buyer requirement.

The findings revealed that although students worked in design department in the organization, their roles and responsibilities differed depending upon the kind of organization. Ones working under a designer/ design house received greater inputs in designing collections, exposure to fashion week activities, design development process. They worked on single piece and achieving highest level of quality and craftsmanship in making that one piece. On the other hand, students who worked in a brand house or export house were exposed to the process and operations related to mass manufacture of garments based on buyer's brief. The focus was on following buyer brief, sourcing materials, sample development and approvals and finally production. Most students reported that the role and tasks fulfilled the aim of internship program as the tasks offered were valuable, interesting, allowed them to use their skills and knowledge and focused on learning (Johari and Bradshaw, 2008).

Expectations:

S2: I expected to learn the overall working of a brand manufacturer, wanted to learn about tech-pack, fabrics, colour combinations and embroideries for mass market'. I learnt more than what I had expected. I was involved in meetings with buyers, allowed to handle sampling unit independently. I gained knowledge about different types of software.

S6: I wanted to learn how a company works, specifically design department, in an organized sector. I was assigned to design and sampling department where my projects related to designing garments and sample development allowed me to understand the systems and processes followed in an export house.

S7: Though I worked in a brand house of my choice, my expectations were not met. I had high hopes from internship. I was engaged in making excel sheets and tags besides assisting my mentor in sample development. I looked forward to greater inputs in design.

S8: My experience at brand house was quite disappointing. I was engaged as assistant designer in the company. I expected to learn about different processes involved in production. No exposure was given on pricing of products and sourcing.

S9: Before joining my internship, I expected to learn and develop understanding of how a designer labels works. I was more than happy when I was selected by a design house as an intern. I developed designs, embroideries for their upcoming collection and looked after design development to sampling to production of final garments. I never expected such detailed exposure.

S12: I expected greater design inputs and relevant tasks. It was disappointing when many times I was asked to lift and shift heavy boxes or do tasks that did not relate to my learning expectations.

The interview responses indicated that internship expectations were partially met for some of the students due to unfavorable experiences. Though students had joined their preferred organizations, the tasks and exposure provided did not match their expectations.

Experiences:

S8: I got opportunity to visit various factories and interact with vendors. The negative aspect was long working hours and 6 days/ week.

S2: Received appreciation and earned respect for my work. I have been asked to join post completion of my degree programme. I did not have any negative experience.

S1O: At the brand house, I had the freedom of exploring the resources to develop collection. But during internship, while getting my samples stitched, sample master left the job and I had to request him endlessly to develop my samples. 
This caused enormous mental stress and developed negativity in me. I was frustrated but somehow, I was able to manage before completion of my internship.

S11: I was able to experience both- a design house and an export house working as my designer also had export division. On the negative, I was frustrated as initially I was assigned to HOME department. Secondly HR teams were mismanaged and sometimes rude to me.

S12: It was a 360 degree experience at the export house where I learnt about design, sampling, quality, getting orders approved corrections and overall functioning. Looking at negative side of my experience, I can say it was bad. Lots of physical activity with no breaks or relaxing time in between. They just wanted work. We were treated as workers sometimes.

S13: I was appreciated by my mentor for my managerial skills and getting work done on time. In my initial days, I misplaced one pattern of a garment which was to be developed urgently for buyer meet. My mentor yelled at me. I really felt insulted in front of others.

S14: The internship has helped me utilize my institutional learning, brought greater clarity to my career goals and preparedness. Involvement in variety of tasks gave me greater confidence about my strengths and abilities.

S15: The experience cannot be attained merely by reading books in closed settings of an institution. I learnt presentation skills, understanding buyer requirement, work under pressure, maintain time lines, and overcome challenges. Working in sampling department required me to interact with different people thus, enhancing my interpersonnel skills and people management skills. In fact, I considered myself more refined now.

S16: Internship is an opportunity to learn those aspects of garment industry functioning that cannot be learnt through text books. The professional environment is all-together different from theoretical lectures. It is full of challenges that are tackled on daily basis. It was really tough time for me when I joined internship as I was not able to cope up with time lines, did mistakes as well. My mentor was always rude and rarely appreciated my work.

The views indicate that internship experience has been a mix of positive and negative experiences. Through educational learning, students are only able to get some idea of how industry functions and they develop high expectations. The gap between their expectations and experiences can affect their interest in learning, motivation, self-initiative and may develop a laid back attitude among students.

\subsection{Suggested Improvements for a Successful Internship}

Study found that respondents considered 2 month duration as a short period for experiential learning. It is suggested that the internship duration should be increased to $4-6$ months. Internship should be structured and designed using a cooperative approach between academia and industry. Mentors should avoid giving mundane tasks. In fact, depending upon the strengths and weaknesses of the student intern, exciting and challenging tasks should be designed (Blumenfeld et al., 1991). Valuable and detailed feedback will help student to bring better understanding and clarity. Respectful treatment and appreciation will motivate student intern to take initiative, generate interest, act responsibly, become loyal and be enthusiastic. Continuous support from academic and industry mentors will foster clarity of thought since the learning process is constantly monitored. The mentors should act as facilitators (Johari and Bradshaw, 2008). Academic mentors should brief and prepare the students for internship. Lack of understanding about company and kind of work expected from students acts as a hurdle in their performance. Academia should work in close connection with industry to identify and incorporate latest as well as future skills in their curricula and internship objectives.

An Internship Cell needs to be incorporated that solely works in tandem with industry by keeping a track of changing job roles, skill and knowledge requirements, internship openings, changes happening in fashion industry, negotiates with companies for motivational stipend scheme, create a repository of local, national and global companies with their internship requirements, conduct 'fashion industry requirement awareness seminars' for students, develop formats that are mailed to students to find their preferences, mapping of student preferences with industry requirements, conduct skill and knowledge test to find best student- company internship match. These suggestions can definitely bring about a drastic change in students perceptions and expectations enabling them to have better internship experiences.

\section{Conclusion}

The findings portrayed that perceptions of students varied as far as their expectations from internship program at fashion companies was concerned. Each student had their own thought process while approaching and selecting the company. Three themes emerged: improvement in KSA, interest in experiential learning, and greater exposure in design field. Our findings are supported by Lee and Woo (2016) who also found that students considered internships as 'an opportunity for hands on experience, qualification for employment, and new beginning'.

As an important outcome, the study found that internship experience proved to be a highly valuable experience for fashion design students as growth was observed in knowledge, skill and attitude, clarity of job roles and responsibilities, types of operations conducted in various departments and actual functioning of the organization, enhanced employment opportunities, networking with potential employers (Petrillose and Montgomery, 1997; Ju et al., 1998; Schutte, 2007). Fashion industry is one that demands long working hours, high level of commitment, motivated and self- driven work force. Internships foster overall development of students through experiential learning and develop ability to correlate their institutional learning with real world working, increased awareness of job roles, responsibilities, processes, and career prospects (Kozar and Hiller, 2015).

Negative experiences during internship can be a loss to fashion industry as such experiences may discourage students from building a career in the industry (Callan, 1997). Disappointments arise due to mundane tasks, irrelevant tasks, simple and non- challenging tasks (Lee and Woo, 2016). Contrary to this, literature also shows that positive experiences during internships strengthen the desire to work in industry (Ju et al., 1998). Students should take their internship opportunity quite seriously depending upon their competencies. They should select internship position that enables them to develop maximum competencies (Walo, 2001). The possibility of student 
getting absorbed in same company after graduation implies a successful internship. It's a window for future career prospects (Collins, 2002).

Study found that design process, fabric knowledge followed by pattern making and garment construction were the academic inputs that had maximum utilization in their job roles. They also specified knowledge gained, skills enhanced and attitude developed during 2 month internship program. Maintaining a journal of daily tasks helped them identify and track the progress of their tasks, flexible learning environment allowed experimentation (Stanforth, 2009). It was also found that students rated internship experience as 'good to very good'. Students were satisfied with the daily tasks given to them and their learning experience. Study showed positive influence on students' perceptions.

\section{References}

Blumenfeld, P.C., E. Soloway, R.W. Marx, J.S. Krajcik, M. Guzdial and A. Palincsar, 1991. Motivating project-based learning: Sustaining the doing, supporting the learning. Educational Psychologist, 26(3-4): 369-398.Available at: https://doi.org/10.1080/00461520.1991.9653139.

Burns, M., 2013. Undergraduate internship expectations: Strategic encouragement of student involvement. Inquiries Journal/ Student Pulse, $5(12)$.

Bye, E. and K.L. Labat, 2005. An integrated strategy for an apparel design curriculum. Journal of Family and Consumer Sciences, 97(4): 6065.

Callan, R., 1997. Supervised work experience in Europe: A profile of UK undergraduate perceptions. International Journal of Contemporary Hospitality Management, 9(1): 35-39.

Collins, A.B., 2002. Gateway to the real world, industrial training: Dilemmas and problems. Tourism Management, 23(1): 93-96.Available at: https://doi.org/10.1016/s0261-5177(01)00058-9.

D'abate, C.P., M.A. Youndt and K.E. Wenzel, 2009. Making the most of an internship: An empirical study of internship satisfaction. Academy of Management Learning \& Education, 8(4): 527-539.Available at: https://doi.org/10.5465/amle.8.4.zqr527.

Edonkumoh, E.V., V. Nwachukwu and A. Emmanuel, 2015. Graduate studnets internship experienceand its impact on practical skills development in LIS education: A survey. Library Philosophy and Practice E-Journal. 1335.

Faerm, S., 2014. From classroom to design room: The transitional experience of th efashion design graduate. Notebooks of the Center for Studies in Design and Communication. Essays, 48: 129-152.

Fox, T., 2001. A sense of place. Caterer and Hotelkeeper, 189(4160): 30-31.

Gavigan, L., 2010. Connecting the classroom with real-world experiences through summer internships. Peer Review, 12(4): 15-19.

Hynie, M., K. Jensen, M. Johnny, J. Wedlock and D. Phipps, 2011. Student internships bridge research to real world problems. Education+ Training, 53(2/3): 237-248.

Johari, A. and A.C. Bradshaw, 2008. Project-based learning in an internship program: A qualitative study of related roles and their motivational attributes. Educational Technology Research and Development, 56(3): 329-359.Available at: https://doi.org/10.1007/s11423-006-9009-2.

Ju, J., D.A. Emenheiser, H.R. Clayton and J.S. Reynolds, 1998. Korean students' perceptions of the effectiveness of their internship experiences in the hospitality industry in Korea. Asia Pacific Journal of Tourism Research, 3(1): 37-44.Available at: https://doi.org/10.1080/10941669908722006.

Kardash, C., 2000. Evaluation of an undergraduate research experience: Perceptions of undergraduate interns and their faculty mentors. Journal of Educational Psychology, 92(1): 191-201.Available at: https://doi.org/10.1037/0022-0663.92.1.191.

Karunaratne, K. and N. Perera, 2015. Students' perception on the effectiveness of industrial internship programme. International Conference on Global Business, Economics, Finance and Social Sciences. Bangkok, Thailand.

Knouse, S.B. and G. Fontenot, 2008. Benefits of the business college internship: A research review. Journal of Employment Counseling, 45(2): 61-66.Available at: https://doi.org/10.1002/j.2161-1920.2008.tb00045.x.

Kozar, J.M. and C.K.Y. Hiller, 2015. The fashion internship experience: Identifying learning outcomes in preparing students for the 'real world'. International Journal of Fashion Design, Technology and Education, 8(1): 3-11.Available at: https://doi.org/10.1080/17543266.2014.974690.

Lee, M. and J. Woo, 2016. Fashion major students' internship experience: Using photo elicitation interviews. International Textile and Apparel Association (ITAA) Annual Conference Proceedings. Iowa State University Digital Repository.

Maertz, C.P.J., P.A. Stoeberl and J. Marks, 2014. Building successful internships: Lessons from the research for interns, schools, and employers. Career Development International, 19(1): 123-142.Available at: https://doi.org/10.1 108/cdi-03-2013-0025.

McMahon, U. and U. Quinn, 1995. Maximizing the hospitality management student work placement experience: A case study. Education+ Training, 37(4): 13-17.Available at: https://doi.org/10.1108/00400919510088870.

Mercan, Ș., M. Aksu, H. Yıldırım and T. Bucak, 2015. Perception of internship on students studying in the field of tourism at undergraduate level: A research at Çanakkale Onsekiz Mart University. Journal of Academic Social Science Studies, 32: 319-333.

Ministry of Textiles, 2018. Garment sector to understand their requirement for capacity building. New Delhi: Ministry of Textiles.

O'Neill, N., 2010. Internships as a high-impact practice: Some reflections on quality. Peer Review, 12(4): 4-8.

Pauzé, E.F., W.A. Johnson and J.L. Miller, 1989. Internship strategy for hospitality management programs. Hospitality Education and Research Journal, 13(3): 301-307.Available at: https://doi.org/10.1177/109634808901300330.

Petrillose, M.J. and R. Montgomery, 1997. An exploratory study of internship practices in hospitality education and industry's perception of the importance of internships in hospitality curriculum. Journal of Hospitality \& Tourism Education, 9(4): 46-51.Available at: https://doi.org/10.1080/10963758.1997.10685352.

Phoebe, W.K., 2010. Determinants of internship effectiveness for university students in Hong Kong. Hong Kong: Hong Kong Baptist University.

Renganathan, S., B.A.K.Z. Ambri and L.C. Su, 2012. Students' perception of industrial internship programme. Education+ Training, 54(2/3): 180-191.Available at: https://doi.org/10.1108/00400911211210288.

Schambach, T. and J. Dirks, 2002. Student perceptions of internship experiences. 17th Annual Conference of the International Academy for Information Management. Barcelona, Spain: ERIC.

Schutte, K., 2007. Journey or destination: A study of experiential education, reflection and cognitive development. Journal of Cooperative Education and Internships, 41(1): 118-128.

Stanforth, N., 2009. Fashion merchandising internships for the millennial generation. International Journal of Fashion Design, Technology and Education, 2(2-3): 91-99.Available at: https://doi.org/10.1080/17543260903348991.

Walo, M., 2001. Assessing the contribution of internship in developing Australian tourism and hospitality students' management competencies. Asia-Pacific Journal of Cooperative Education, 2(2): 12-28. 